\title{
Bitcoin in the economics and finance literature: a survey
}

\author{
Parthajit Kayal ${ }^{1}$ (D) Purnima Rohilla ${ }^{1}$
}

Received: 2 August 2020 / Accepted: 18 May 2021 / Published online: 3 June 2021

(c) The Author(s), under exclusive licence to Springer Nature Switzerland AG 2021

\begin{abstract}
This paper provides a review of the literature on key matters related to the popular cryptocurrency Bitcoin. Another key motivation of this paper is to understand the underlying principle of this digital currency from the economic and financial point of view. For the survey to be comprehensive, the paper is categorized into varied themes: price dynamics, volatility, bubble dynamics, mode of recognition in the financial market, efficiency, economics, social media and investor sentiment, and lastly regulation and legality. We argue that Bitcoin is still in an embryonic phase and needs to evolve with time especially keeping in pace with technological advancements. It should be robust to get accepted as an alternative currency and be able to prevent any fraudulent exploitation.
\end{abstract}

Keywords Cryptocurrency · Bitcoin · Price dynamics · Volatility $\cdot$ Bubble dynamics $\cdot$ Social media and investor sentiment

\section{Introduction}

Bitcoin is a cryptocurrency (or digital currency) formulated on the concept of "peerto-peer" (P2P) network (Nakamoto 2008). This invention is credited to a pseudonymous software developer or maybe a hacker named "Satoshi Nakamoto". The key intention was to create a transaction system free from intervention by any central or monetary authority, be based on a mathematical algorithm instead of "third-party trust", payments can be done electronically in a protected, verifiable and incontrovertible way. The application of this idea implies a payment system that all transactions happen directly between the owner and the receiver and is broadcast through a P2P network. Despite the information being public, the identity of the user is

Parthajit Kayal

parthajitkayal@gmail.com

Purnima Rohilla

purnimarohilla96@gmail.com

1 Madras School of Economics (MSE), Gandhi Mandapam Road, Behind Government Data Centre, Kottur, Chennai 600025, India 
anonymous. The coin is mined to collect information in the form of "blocks" and each block contains information with respect to the current transaction and the previous block. This links every current block to the first block. All recorded transactions on the block are verified by the principle of Proof-of-Work. It is almost impossible to change the Bitcoin software unless the majority of participants agree to do so. A hacker or user with criminal intention requires enormous computational power to alter this arrangement. Do such fundamentally strong principles make this a trueblue system? The academic literature has a varying response to this question. The aim of this paper to consolidate evaluations and interpretations of various academicians who have probed into the existence and working of the Bitcoin payment system. The motivation behind this literature survey is to integrate the existing research work in this area and possibly present it as a starting point for future researchers to use this study as a preliminary pathfinder. We aim to address some central ideas like price and volatility dynamics; economics and efficiency of the system; and financial aspects and regulation. Kindly note that this work does not regard technicalities of blockchain or mining strategies which serve the working of the Bitcoin payment system. The key focus is to address the questions from economics and finance belief through simplified discussion. Therefore, the themes of our work are chosen to be in line with Economic and Finance theory and literature. We have tried to cover all the important work published at the time of completion of this work. The major criteria we have used for paper selection are minimum of 10 citations and quality of the journal it is published with. Most of the journals are graded as B and above as per the Australian Business Deans Council ranking. However, we have made exceptions for some working papers if they had a high citation. Subsequently, the paper has been structured as follows: "Price dynamics" draws attention to volatility that exists in the Bitcoin market. It also addresses a key question on speculation of Bitcoin being a mere bubble. "Volatility and bubbles" elucidates the economics behind the entire system and reviews whether the system is efficient or not. "Economics and efficiency of Bitcoin" analyses the crucial "Asset vs Currency" debate that keeps contouring around the Bitcoin. It also throws light on the speculative hedging and investment virtues with Bitcoin. "Bitcoin as currency vs asset" calls attention to the impact of social media on investor sentiments and the traceable consumer behavior towards the Bitcoin. "Social media and investor sentiment" focuses on the regulatory and legal aspects of the Bitcoin system and the threats it faces in terms of cyber-crimes. Finally, the paper presents conclusions and the scope for future work.

\section{Price dynamics}

Why does Bitcoin exactly have any value? It is not backed by any regulatory authority nor does it have any asset backing. It is operating in a virtual space through some complicated mathematical algorithm like in some science fiction. It is not, yet a very widely accepted payment system. It has been associated with some evasions in terms of legality. And yet, it continues to survive to show comprehensive price fluctuations ever since its formal existence in the virtual market. Prices of any commodity are determined by basic economic indicators or drivers such as utility, supply, demand, 
and scarcity. These factors do determine the price of Bitcoin but are also with several other factors which might be very absurd to be considered for any other fiat currency. For example, a Google search of Dollar will not impact the value and volume of it, but it can possibly drive the prices of a cryptocurrency (Aalborg et al. 2019).

An extensive amount of academic research has been done to determine what gives Bitcoin its value or what are the factors behind its constantly fluctuating prices. The demand-supply theory is the most common principle used in literature to determine the price of Bitcoin. "Inelastic demand and tight supply" result in soaring prices of Bitcoin as found by Blundell-Wignall (2014). The price determination model used is based on the "medium of exchange" role of Bitcoin. They form that the demand curve and supply functions are derived from the advantages or benefits of using Bitcoin. However, the prices can fall to zero if these benefits are taken away by the government or the coins are hampered by fraudulent activities or if a better alternative emerges in the market. The transaction volume also proves to be a significant demand driving ingredient implying that the transactional needs of users drive up the prices. The supply-side variables, on the other hand, prove to be insignificant in driving the prices of this unregulated contemporary currency. This phenomenon has been explained by Polasik et al. (2015) that it is because the bitcoin is governed by a mathematical algorithm and any expected future change is already reflected in the current prices. Kristoufek (2015) conducts a similar analysis by constructing a demand variable as a trade exchange ratio and incorporating the method of wavelength coherent analysis. The study finds that the price leads the Trade exchange ratio in the short run but not in the longer run. It means that Bitcoin does appreciate in the long run when used for more non-exchange transactions while in the short run the price boosts the exchange-based transactions. The supply-side factor remains difficult to be determined as the future money supply is also already reflected in the current prices because of a known algorithm. This relationship between the expected future supply of Bitcoin and its prices remains trivial (Polasik et al. 2015).

Using Economic Freedom Index, Viglione (2015) studies the role of governance and other related factors in determining the price of Bitcoin as measured by the willingness of users to pay a premium. This work exhibits that real interest rates, tax burden, and investment freedom across different countries is significant in determining Bitcoin prices. In contrast, inflation rates and monetary freedom across boundaries have no impact on Bitcoin prices.

Price information can often be taken from the exchanges the Bitcoins are trading on as noted by Brandvold et al. (2015). They find that Mt. Gox dominated the price discovery and sharing of information Bitcoin (Mt. Gox has now ceased to exist due to malicious activities). They also document that other smaller exchanges, such as Btc-e, are better at providing price information during market shock.

Bitcoin being a digital currency needs to be analyzed from a further perspective than just as an ordinary currency. Both the traditional determinants of currency prices and factors specific to digital currency are analyzed by Ciaian and Rajcaniova (2016). They examine if Bitcoin has the characteristics such as a medium of exchange, a unit of account and a store of value. They argue that the attractiveness of Bitcoin is the main driver of its' price and Bitcoin cannot compete with standard currencies due to its speculative nature. 
Later Athey et al. (2016) build a model to examine the equilibrium prices under two different scenarios. First in the absence of an investor and second by including an investor with certain characteristics in the model. They demonstrate the existence of a unique equilibrium for Bitcoin prices defined by economic forces (supply and demand) and show that the inclusion of an investor in the model gives a dynamic equilibrium. In their explanation, the fluctuation In Bitcoin prices is due to associated market expectations. However, Griffin and Shams (2020) observe that Bitcoin price reflects much more than just standard supply/demand and fundamental news. They argue that price manipulation has substantial distortive effects on Bitcoin. In a theoretical work, Bouoiyour et al. (2016) use the technique of Empirical Mode Decomposition to extract Intrinsic Mode Function (IMF) of time series data. The model first decomposes the time series into different IMFs arranging it from high to low frequency and then composes these IMFs into the fluctuating process. The findings exhibit that the slowly fluctuating (long term) components are more influential on Bitcoin price than swiftly fluctuating (short term) components. This varying short-run versus long-run results are also reflected in the empirical study by Wang et al. (2016). They find stock price index, oil prices, and daily traded volume to have a stable relationship with Bitcoin price in the long term but in the short-run it gets dynamic. A change in stock price index significantly affects Bitcoin prices as the investors tend to shift in and out of the market when experiencing variations. Changes in oil prices and trading volume, on the other hand, do not have much impact. The Bitcoin price is positively related to trading volume but negatively related to the stock price index, and the oil price. Bitcoin prices were further studied to see with respect to Bitcoin futures by Baur and Dimpfl (2019) and by trading platform by Pagnottoni and Dimpfl (2019). The former observes that Bitcoin spot price leads the futures price and later finds Chinese platforms like OKCoin and BTC China are the leader in price discovery of Bitcoin. Further, Kapor and Olmo (2019) show that Bitcoin futures and spot log-price have predictive drives for the Bitcoin spot price.

With increasing popularity and acceptance in the era of IoT (internet of things), Bitcoin is gaining more attention and more scrutiny. Being operated on an unregulated mechanism makes it highly vulnerable to manipulations. This issue has been highlighted by Gandal et al. (2018) and Griffin and Shams (2020). Authors of the former work set up an association between suspicious trading and resulting price fluctuations. Their study pivots around the much controversial suspicious activity on Mt. Gox in early 2014 and finds that Bitcoin prices rose an approximately 80\% of the days on which suspicious trading activity was recorded, while it rose on a comparatively lesser number of days, $55 \%$ in which no such suspicious activity was observed. Looking at intraday price dynamics, Eross et al. (2019) observe that over time, Bitcoin returns have increased, while trading volume, liquidity and volatility varied markedly.

Price clustering is a phenomenon where prices tend to congregate around some specific set of values, usually whole digits. This phenomenon has been examined by Urquhart (2017) to check whether the cluster at a round number is being approached by rising or falling prices, or other relevant conditions that might influence the reaction. The price reaction, after round numbers show that in one, two, three, five, and 
ten days before a round number from rising prices, the returns are positively and statistically significant. However, there is no significant evidence of a return pattern after round numbers, but there is evidence of an insignificant next day negative reaction after round numbers. Further, clustering increases as prices and volume increase. In a recent finding, Alaoui et al. (2019) observe that changes in the Bitcoin prices and trading volume mutually interact in a nonlinear way. Looking at geographically defined markets, Panagiotidis et al. (2019) observe increased impact of Asian markets on bitcoin compared to other geographical markets.

However, most of these studies have contrasting findings due to differences in methodologies. Further results are also time-dependent and far from being stable due to the lack of long-term data.

\section{Volatility and bubbles}

Price fluctuations, if are continuously going through bouts of sudden rise and fall can lead to volatility in the Bitcoin market. The volatile market can give higher returns and alternatively pull-down invested capital to zero in the worst-case scenario.

This hype around the volatility of Bitcoin and whether its existence is substantial is audited by Sapuric and Kokkinaki (2014) by comparing its exchange rate with other established currencies. They use three parameters: change in the exchange rate, annualized volatility, and adjusted returns to show that the acclaimed volatility of Bitcoin in the literature is because it ignores the trading volume. The Bitcoin has relatively lower trading volume due to which the Bitcoin exchange rate faces unavoidable shocks and hence, so does its price. A study by Bouoiyour and Selmi (2015) examines extreme volatilities of Bitcoin prices. They state that bad or negative news has a greater effect on the volatility of Bitcoin prices than good or positive news and is highly driven by presumptions of the market participants. Consistent with a similar view, Aysan et al. (2019) examine the predictive power of global geopolitical risks (GPR index) on Bitcoin returns and volatility. They show that Bitcoin returns and volatility are negatively and positively related to GPR index. Further, Su et al. (2020) find the Bitcoin market to be a leading indicator of the global geopolitical situation. Given that Bitcoin prices reflect global geopolitical risk and investors react sharply to this risk, Chevapatrakul and Mascia (2019) report overreaction in the Bitcoin market and argue that Bitcoin investors overreact during days of sharp declines and sharp rallies.

There has been a widespread debate among academicians whether the Bitcoin is an asset or a currency or a commodity. We explore the literature in wider detail in later sections but highlight the common ground between the three in terms of volatility and stability. Dyhrberg (2016a) draws a parallel between Bitcoin, currency, and gold. They argue that Bitcoin lies somewhere between a commodity and a currency as it acts like a currency due to its medium of exchange virtue and its reaction to federal fund rates. Taking into account the hedging capabilities of Bitcoin or its reactions to the news, they claim that Bitcoin mirrors gold. Klein et al. (2018) also do a comparative analysis of Bitcoin with gold and other precious metals and find a contrasting result. They find a similarity between Bitcoin and gold (and other 
precious metals) in terms of response to market shocks: both have an asymmetric response. However, from a market linkage point of view, the study exhibits that Bitcoin behaves completely diverse from Gold. During market distress, while the Gold remains relatively steady Bitcoin tends to decline amidst facing market shocks. It leads us to look at the safe haven properties of Bitcoin.

The safe-haven property of Bitcoin is examined by Bouri et al. (2016) by studying the relationship between change in price returns and volatility using a daily database of prices divided into two phases i.e., before and after the 2013 crash. They show that there exists a positive relation between return shocks and volatility in the precrash period which reflected upon the safe haven property of Bitcoin. However, the post-crash period witnessed a negative relationship thereby suggesting that Bitcoin lost its credibility as a safe investment and hedging instrument among the investors. However, in a recent study, Bouri et al. (2020) examine gold, commodities, and Bitcoin as safe havens for stocks to find Bitcoin to be superior over gold and commodities. However, looking at the safe haven characteristics of Bitcoin during the recent coronavirus pandemic, two separate studies (Chen et al. 2020; Conlon and McGee 2020) find Bitcoin not to be a safe haven during market turbulence. A similar observation was made by Matkovskyy and Jalan (2019) as they find riskaverse investors moving away from Bitcoin markets to safe financial assets during crisis periods. Bouoiyour and Selmi (2016) also, study the volatility trend of Bitcoin using price data over two sub-periods: from 2010 to 14 and from 2015 to 16 . Their findings reveal that the first period to be explosive due to high volatility while the second period is relatively stable. In addition, they also report that price dynamics is more responsive to bad news than it is to the good news (similar to the findings of Bouoiyour and Selmi 2015).

Post any economic or financial crash, there is widespread panic among the investors, and their opinions about the market take a back seat. A feared investor sentiment is not good for the market progression as it can further deteriorate the conditions. The investor sentiment does affect the volatility of Bitcoin and has been empirically examined by Bukovina and Martiček (2016) for the period 2013-2015, i.e., right after the crash of 2013. They find that the impact of sentiment is higher during the periods of high volatility and bubble period especially, for positive sentiment. Bariviera et al. (2017) makes a comparison of Bitcoin with standard currencies and focuses on the analysis of returns from 2011 to 2017. Their study shows that Bitcoin faces large volatility. However, the volatility is getting reduced and stabilized over time. A similar observation is made by Kayal and Balasubramanian (2021) in a very recent study.

In another comparative analysis against standard currencies, Baur and Dimplf (2017) examine the volatility of Bitcoin and find it to be thirty times more volatile than other currencies (US dollars, Euro and Yen). They declare Bitcoin as unfit to be used as currency since the high volatility feature adversely affects its store of the value property. But since Bitcoin is characterized by historical price movements and expected future returns, it can still act as an investment instrument. In a comparison with major currency exchange, Pichl and Kaizoji (2017) find Bitcoin prices to be more volatile than EUR-USD exchange. They also highlight that Bitcoin experience a higher number of bubbles and crashes. 
Balcilar et al. (2017) analyse the causal relationship between trading volume and Bitcoin return and volatility for the period of 2011 and 2016 by incorporating structural breaks as well as non-linearity in prices. The study demonstrates that the volume can predict the returns when the market is in normal mode i.e., around the median of the conditional distribution. But it, cannot predict the volatility. However, when the market is bullish or bearish i.e., either performing too bad or too good, the volume has no role in predicting even the returns. In this case, it can be better predicted by past lags of returns. A similar observation was made in a recent work by Aalborg et al. (2019). They observe trading volume partly explain the volatility.

A few studies claim that the crash of 2013 was due to a bundle of reason such as a negative sentiment among investors, speculative trading, suspicious trading, etc. Blau (2017), however, finds that speculative trading was not a reason behind the crash of 2013 and neither was it responsible for the high volatility of the Bitcoin price during the period. Contrary to many other researchers, the author dispute that there was no existence of a bubble and that Bitcoin could be viable as a currency rather than just being a speculative instrument.

By now, we know that Bitcoin is a sensitive instrument. Its price can fluctuate and tends to be highly volatile. The price crash of 2013 hints at the possibility of the presence of bubbles in the Bitcoin market which eventually came down crashing. A quite a few academicians believe that Bitcoin is nothing but a mere bubble. The price crash of 2013 was simply a foretaste of what lies ahead. Remember the housing market bubble and its consequences? The Bitcoin market might be on its path to face a similar bitter end. Given that it is establishing and gaining popularity among investors especially the newbies, a bubble burst will be shattering. Here are a few pieces of evidence from the literature for and against the claim of the Bitcoin market being a bubble.

The role of social interactions in creating price bubbles in the Bitcoin market has been analysed by Garcia et al. (2014). The study uses tries to quantify and analyse four socio-economic signals: price on online exchanges, volume of word-of-mouth communication in online social media, the volume of information search, and user base growth. They document that the word of mouth and expanding Bitcoin user base are significant influent on the existence of a pricing bubble. This could be explained as follows: the media reports a price increase which further triggers search activities among investors. It increases investors' interest to buy Bitcoin thereby increasing the demand and finally resulting in a surge price. This attracts new investors thus increasing the user base. Another important finding is that user search activity responds more to negative shocks (bad news). Such a search spike can result in a price drop as well. A similar claim is made by Gronwald (2019) as the author explains the movements in Bitcoin prices by demand shocks for Bitcoin. A study by Cheah and Fry (2015) finds that the 'Bitcoin prices do exhibit rich and volatile market dynamics and that the Bitcoin market is subjected to speculative bubbles for the period between 2010 and 2014. The studies identify that a bubble existed just before the crash of 2013. This was contradicted by the findings of Blau (2017). Another confirmation of the existence of bubbles during 2013 was done by Cheung et al. (2015). The study uses the Phillips et al. (2013) method which is robust in detecting bubbles to find evidence of a number of bubbles (a combination of short-lived and 
long-lasting). Using a similar method, Corbett et al. (2018) also examine the existence of a price bubble in the Bitcoin market as well as attempt to date stamp them. They analyse the data using an ex ante method which detects exuberance in asset price series during periods of inflation. Further, they develop a dating strategy to identify the origination and termination points of bubbles using backward regression techniques. As per the finding's Bitcoin does show bubble behavior around the turning point of 2013/14. However, the method fails to prove the much recent price breakouts (around 2017) to be a bubble. A similar observation was made in recent work by Chaim and Laurini (2019) as they claim Bitcoin was in the bubble phase during early 2013 to mid-2014, but, interestingly, not in late 2017. In a recent work, Geuder et al. (2019) examine the Bitcoin prices during the years 2016-2018. They underline that Bitcoin's bubble behavior is common and reoccurring. However, they also did not find any evidence of bubble behaviour after the time point December 6, 2017. Further, Cagli (2019) observes Bitcoin along with other cryptocurrencies to exhibit explosive behaviour.

Fry and Cheah (2016) incorporate econophysics to build models for financial bubbles and crashes using statistical physics and mathematical finance. The study asserts evidence of a negative bubble around the year 2014 in the largest cryptocurrency markets, i.e., Bitcoin and Ripple. It also finds a very evident spillover from the Ripple to Bitcoin which is held responsible for the recent price falls of Bitcoin. This has highlighted the concern over the stiff competition among cryptocurrencies especially for Bitcoin from more flexible options available in markets. In another study, Fry (2018) builds rationale models for Bitcoin and other cryptocurrencies to incorporate heavy tail probabilities and the probability of a complete collapse in asset prices. The model is based on the assumption that the intrinsic rate of return and the intrinsic level of risk are asymptotically constant. The study also exhibits a link between number of Google searches and degree of speculation using Google Relative Search Trends. Further, the author observes that the number of searches declines as the bubble nears its end.

\section{Economics and efficiency of Bitcoin}

Bitcoin has presented itself as a highly innovative and attractive digital currency. A major difficulty among new users or researchers is to understand its design aspects and the economics behind its existence. It has only been a decade since it came into existence. There is extensive literature trying to examine whether it is an efficient means of payment.

First, it is important to understand the economics behind Bitcoin. This virtual currency has absolutely no central backing or point of trust. Its feature of being decentralized attracts individuals who want a "freely traded currency" and stay away from any intermediators such as the bank, or the government (Barber et al. 2012; Bohme et al. 2015). Both these papers outline a few more similarities such as the incentivized system of Bitcoin, fixed or predictable supply and anonymity. The fixed supply of Bitcoin as noted before is due to its creation through mathematical algorithms. However, fixed, supply poses some major problems which can create 
an imbalance in the macroeconomy if the transaction volume increases indefinitely. Further, Bitcoin may have a fixed supply but the digital currency market is not fixed overall. There are more than two thousand digital currencies available to date and new currencies are getting launched often.

As noted by Yermack (2015) and Ali et al. (2014), a fixed supply will lead to deflation which will, in turn, lead to high welfare destroying volatility. It will be a difficult task indeed to match the variation in demand. Ali et al. (2014) propose that a more flexible system is required to respond to varying demands. One way is to have an adjustable growth rate of currency supply and another is a decentralized voting mechanism. While some researchers predict a possibility of deflation, Lo and Wang (2014) throw light on a possible scenario of hyperinflation if the central bank chooses to oversupply currency. These possible scenarios of deflation and inflation are ruled out by Iwamura et al. (2014b) as they argue that fixed supply will only negatively impact the profitability of mining activity but not lead to a deflation-like situation.

Although the supply of Bitcoin is fixed and will converge to a finite limit, it is indestructible. Evans (2014) refers to Bitcoin and other digital currencies as a longlived asset of which the value at any point in time reflects its expectations about the future value and a change in this expectation can change the value further. The study also claims that even though Bitcoin appears as highly volatile in the short-run, it will stabilize over a longer period of time. The participants collect more information about demand and supply as well as utility being derived from the Bitcoin use and hence become more efficient. This has been further emphasized by Dwyer (2015) and also confirms the existence of equilibrium in the Bitcoin market to agree with the theoretical results of Marimon et al. (2012). The theoretical framework by Dwyer (2015) lists out the demand and supply factors of Bitcoin in a structured way and, its usage in terms of exchangeability with goods and services in comparison with its competing currencies. The determination of equilibrium has been of keen interest among the scholars and as seen earlier, it is constructed on varying factors of the market. Another such model constructed by Chiu and Koeppl (2017) gives more holistic requirements for an equilibrium to exist in the Bitcoin market. They scheme the conditions to be inclusive of buyer's utility and miner's utility and prove that the equilibrium exists when there is a sufficiently large number of buyers. Schilling and Uhlig (2019) construct an equilibrium state and find that the Central banks via appropriate monetary policies keep the value of Dollar constant and the production/ supply of Bitcoin is by default decentralized through its algorithmic mechanism.

How well, the Bitcoin market follows key economic principles to determine the efficiency of the same. Most of the literature has established that the Bitcoin market is volatile due to the fact it is in its nascent stage. In the longer run, the price stabilizes, volatilities dampen and the existence of bubble diminishes. The entire Bitcoin transaction mechanism is based on blockchain technology and more or less every form of technology evolves over time to get better. A direct implication of this noted by $\mathrm{Li}$ and Wang (2017) is that the mining technology gets better in the long run thereby reducing the mining difficulty and making the entire process more efficient. An older study by Houy (2014) analyses the economics of Bitcoin transaction fees 
and finds that efficiency is enhanced by implementing transaction fee and limited block size in mining.

Apart from understanding the economics of Bitcoin for analysing its efficiency, it is also important for formulating the underlying guidelines of financial reporting of Bitcoin transactions. Although Tan and Low (2017) find that Bitcoin transaction requires no new accounting principle but requires an authoritative interpretation of existing accounting principles with respect to Bitcoin.

The existing literature also highlights the inefficiency aspect of Bitcoin. A twoperiod analysis by Urquhart (2016) displays that the Bitcoin market is an overall inefficient market but, on its path, to become an efficient one as it matures over the longer run. A similar result is obtained by Bariviera (2017), Kurihara and Fukushima (2017), Nadarajah and Chu (2017) and Sensoy (2019).

\section{Bitcoin as currency vs asset}

The blockchain technology makes every transaction of Bitcoin safe, verified and almost anonymous. Bitcoin is unregulated and the supply is predictable due to the application of a mathematical algorithm. The user base has expanded since its inception and has a long way to go (given it survives all the hardships). Any financial instrument can have two fundamental uses: a store of value and a medium of exchange. The question arises which of the two dominates Bitcoin. The "Asset vs Currency" debate has been a hot topic of discussion among scholars. Since the Bitcoin price is characterized by high price fluctuations, users may use it only as a speculative instrument. Users can buy Bitcoins and sell them when the exchange rate rises and thereby earning high returns.

Before formerly answering whether Bitcoin is used as an asset or currency, it is imperative to learn whether existing research has given it a green signal to be qualified as an uncompromising currency. The ability of Bitcoins to avoid the interference brought by banks, centralized payment systems and governments has been discussed by Maurer et al. (2013) as they refer to two main features of "privatisation" of identities that transacting Bitcoins and its "digital metallism." To them, Bitcoin also promises solidity, materiality, stability, anonymity, and community. The "proofof-work" principle has been scrutinized by Becker et al. (2013) and points out that Bitcoin payment system is secure when no single party controls more than $50 \%$ of the network's computing power. It does criticize that electricity consumption needed to carry out high computational problem leaves behind a carbon footprint.

Carrick (2016) considers Bitcoin as highly effective for transactions and can be used in conjunction with fiat currencies i.e., it is not a substitute but a compliment. Bitcoin can be balanced out between being a medium of exchange and a speculative instrument depending upon the risk-holding capacity of users (Luther and White 2014). Bitcoin has been referred to as gold in a virtual environment by Rogojanu and Badea (2014). They have listed the advantages and disadvantages of Bitcoin keeping in mind the ideal properties of a currency given by the Nobel Prize Laureate FA Hayek. The advantages of Bitcoin include tie savings, business flexibility, cost minimisation, avoids third-party commissions, does not generate inflation, the 
anonymity of traders, and escapes central intervention. The major disadvantages subsume extreme volatility of price, uncontrolled transaction, large speculative attacks that can cause negative effects, limited confidence in Bitcoin, and increased vulnerability of cyber theft. Resembling pros and cons have been quested by Richter et al. (2015) and Lo and Wang (2014). They address the shortcomings in the huge hard drive space required to store the entire blockchain and the resource cost of mining constantly growing. Legitimacy issues of the Bitcoin financial system have been discussed in workings of Weber (2014) which draws attention to the failure of Bitcoin to fulfill multifunctionality of currency and stability. In another allied study by Weber (2014), the author recommends the need to create a mass demand for Bitcoin to have a parallel economy and later serve the instability and deflationary pressure issues. Testing against standard definitions of money, Kubat (2015) does not pass Bitcoin to be an alternative currency and asserts that it cannot function as a store value of money. Further, Bjerg (2016) hails Bitcoin as a digital Ponzi scheme down the road if it fails to prove itself as cheap, efficient, ingenious, democratic, and a stable payment system. Findings in agreement with the above have been enumerated in the workings of Ciaian et al. (2016) and Luther (2016).

A few characteristics of Bitcoin which make it a good currency substitute are discussed by Chowdhury and Mendelson (2013). Bitcoin has a lower transaction cost and is an inexpensive fund transfer system. It allows remittances at less cost (Folkinshteyn et al. 2015) and helps improve access to financial services. Moreover, it has no strict capital controls and no intervention by a central authority, thus no scope of reversal of transactions. However, it lacks liquidity and yet to achieve a widespread user base. Being decentralized, there is absolutely no guarantee of any help or resort in case of a failure and is thereby difficult to safeguard it from various types of risk. It is such drawbacks that limit people from using it as a hardcore currency. The economic rationales are required in the long run for bitcoin to become a currency or asset (Iwamura et al. 2014a; b).

New users generally do not intend to spend Bitcoin currency for buying goods and services as indicated in studies by Glaser et al. (2014) and is instead more widely used as speculative instruments (Kajtazia and Moro 2019). This finding is further supported by Baur et al. $(2016,2018)$ The latter study analyses the statistical property's Bitcoin and compares it with other assets such as stocks, commodities, and bonds in both financially stable and unstable periods. The author finds Bitcoin to be uncorrelated with other traditional assets. It is mostly held by users for speculative and investment purposes.

This leads to another interesting insight. If the majority of users use it for speculative purposes, can there be the one influencing the Bitcoin price and returns? This has been examined by Baek and Elbeck (2015). They show that the returns are independent of external economic factors. It is the market participants that internally drive the market returns which make it a front runner as a speculative instrument.

What drives users to invest in Bitcoin or use it as a speculative instrument? It is highly volatile and some argue it to be a bubble and yet there is a huge rise in the number of users. A finance principle will tell us that high volatility implies high returns. Brière et al. (2015) advocate that high risk needs to be compensated by high returns. They also find that Bitcoin is weakly correlated with other assets. 
Bouri et al. (2017) define a diversifier as one, which has a weak positive correlation with other assets such as gold. Thus, the inclusion of Bitcoin in the portfolio makes it well diversified. In a more detailed work, Bedi and Nashier (2020) examine Bitcoin's investment credentials through a cross-currency analysis. They find that Bitcoin exhibits striking variation in terms of the diversification benefits. While analysing Bitcoin price behaviour during the recent coronavirus pandemic, Conlon and McGee (2020) find Bitcoin substantially increases portfolio downside risk, especially during market turbulence.

Apart from being useful as a diversifying instrument, it is also utilized as a hedging device. Gold is a common hedging instrument used widely and Bitcoin is often studied compared to the same, in terms of hedging and volatility. The hedging capabilities of Bitcoin have been analysed by Dyhrberg (2016b) against Financial Times Stock Exchange Index and the American dollar. This study indicates that Bitcoin can find a good spot in the list of assets used for hedging. In a recent study, Akhtaruzzaman et al. (2020) observe that Bitcoin can be used to hedge the risk against industry sectors and bond index. Pal and Mitra (2019) also examine Bitcoin's hedging effectiveness. Adding further to the literature, Fang et al. (2019) notice that Bitcoin's hedging effectiveness against global equities and global bonds becomes prominent if we consider the level of global economic policy uncertainty. Further, Bitcoin derivative instruments are also found to be hedging effective (Alexander et al. 2020). In contrast, Beneki et al. (2019) argue that Bitcoin's hedging abilities have reduced significantly over the recent periods due to increased policy uncertainty. In contrast, Chan et al. (2019) find Bitcoin to be an effective strong dynamic hedge using frequency dependence approach on monthly data for the period of 2010-2017.

Bitcoin has also been assessed against energy commodities by Bouri et al. (2017) since electricity is a key input in Bitcoin transactions and can be expected to have different results from non-energy commodities such as gold. The analysis is done in two sub-periods (before and after the 2013 crash) comparing Bitcoin index with energy and non-energy commodity indices. They find that Bitcoin shows hedging as well as safe-haven capabilities for both the indices for the entire period and before the crash period but only as a diversifier in the post-crash period. The literature proposes that Bitcoin is an attractive investment choice especially, in diversification and hedging. Recent work like Giudici and Abu-Hashish (2019), Symitsia and Chalvatzis (2019), Kilber et al. (2019), Urquhart and Zhang (2019), and Wang Et Al. (2019) also confirm the same. Symitsi and Chalvatzis (2018) observe the presence of spillover effects from Bitcoin to energy-technology companies. The study also detects bi-directional asymmetric shock spillovers. In the short run, there is a spillover from technology stocks to Bitcoin while in the longer run Bitcoin volatility affects the energy companies. The investible feature is confirmed by Dyhrberg et al. (2018) in their analysis of transaction cost and intraday trading patterns on the Bitcoin-USD exchange rate. The findings are especially in favour of retail size traders. A very recent study by Zeng et al. (2020) further observes spillover effects (asymmetric) between Bitcoin and conventional assets. 


\section{Social media and investor sentiment}

Unlike our usual currency, Bitcoin is not driven by any central monetary authority. It is free from regulatory norms and has no government intervention. Instead, the Bitcoin market is user-driven. It has a value till the users think it has some worth or can be converted to currency at a higher return. Thus, it can be said to be driven by future expectations of the Bitcoin holders and future investors. As noted in previous sections, the Bitcoin supply and demand are independent of macroeconomic factors in contrast to standard currencies. The supply is fixed or controlled by mathematical algorithm and demand depends on the future expectations on Bitcoin returns. Bitcoin being a digital currency cannot be isolated from the protagonist of its existence: the internet. In this digital era, an individual feeds his curiosity through web browsing as it gives an instant answer. A high interest in Bitcoin could imply enormous web searches on the internet and this interest influences the expectations of users and thereby the Bitcoin price (or demand and supply). This is a slippery road as a rational person will react positively to good news and negatively to a bad one. Thus, a piece of false or fake news can blow out easily and thereby causing unrest in the Bitcoin market.

Academicians have analyzed the role of media, social media and internet in driving the Bitcoin price or causing high volatility in the market. A bidirectional relationship between web searches (Google and Wikipedia) and prices of Bitcoin was examined by Kristoufek (2013). The interest of users was captured by internet searches to find that web queries influenced prices and prices, in turn, influenced the number of searches. Another study incorporating Google searches done by Yelowitz and Wilson (2015) find that computer programming and illegal activity search terms are positively correlated with Bitcoin interest. A similar price analysis based on the popularity of Bitcoin was done by Polasik et al. (2015). The key determinant of this result is the tone score used in the sentiment analysis. It implies that if the tone of an article is on a praising note the prices are observed to be increasing while the tone is denouncing the prices went down. The findings also present that the return increased as Google searches increased and when the number of articles on Bitcoin in the newspaper appeared more frequently. Contributions of impacts of social media on the Bitcoin market are more broadly analyzed by Feng Mai et al. (2015). They believe that social media can provide key insights into the general public's acceptance of Bitcoin. The study observes that a bullish post predicts positive returns, and a bearish post predicts negative returns. A higher disagreement among the public reflected in the comments leads to a higher exchange trading volume. Further, transaction volumes can be predicted using the messages and comments posted online. Garcia and Schweitzer (2015) highlight the scope of profit-making through social media signals by combining statistical analysis and back setting server. The study uses the framework to incorporate Google searches, Twitter feeds and opinion polarization (to echo the emotions), and opinions to predict financial returns and derive large profits. Dastgir et al. (2019) observe a bi-directional causal relationship between Bitcoin attention (measured by the Google Trends search queries) and Bitcoin returns. 
Shen et al. (2019) find the number of tweets to be a significant driver of Bitcoin's trading volume and realized volatility.

The application of users' comment analysis is also validated by Kim et al. (2016) to predict future prices and the effective number of transactions among users. In another analysis by Kim et al. (2017), a model based on deep learning was developed to predict Bitcoin count and prices. Twitter has been interpreted as a 'virtual trading floor that emotionally reflects Bitcoin's market movement' in a study by Kaminski (2014). The study applies static Pearson correlation methods and Granger causality test to a possible relationship between Twitter posts and Bitcoin market indicators. While the former confirms a moderate correlation, the latter test rejects any statistical significance for Twitter signals as a predictor of Bitcoin market indicators. A link between the number of Google searches and the degree of speculation using Google Relative Search Trends was specified by Fry (2018). A recent study by Chen et al. (2020) focuses on the fear sentiment caused by the coronavirus pandemic. They find Bitcoin to be impacted negatively as returns fell with high trading volume during the pandemic. Further, they argue that Bitcoin does not act as a safe haven during the pandemic. Other similar works like Shahzad et al. (2019), Smales (2019), Shahzad et al. (2020), and Wu et al. (2019) draw similar conclusions as they find Bitcoin is not a strong safe-haven instrument.

\section{Regulation, legality and cybercrime}

Bitcoin works on a decentralized mechanism that allows it to be isolated from any intervention by a regulatory authority. It does overcome the difficulty of transport and storage compared to standard currency. However, the latter still carries more liquidity and trust among people. Bitcoin has been endorsed to be anonymous in terms of the identity of users and each transaction is irreversible (Bradbury, 2013). The literature, however, demonstrates that Bitcoin is not completely but anonymous as Bitcoin transaction history is freely available when one joins the peer-to-peer network to ensure the prevention of double-spending. This has been explained by Reid and Harrigan (2013) also. They point this out along with other features such as several inputs and outputs and multiple public keys. Further scrutiny of the network structure used in Bitcoin transactions has led them to conclude that there is a possibility of associating several public keys with each other and thus arising a possibility of knowing the activities of users. This semi-anonymous feature is supported in a study by Androulaki et al. (2013) that analyses the genuineness of Bitcoin system by simulating in a university setting to mimic its working with real-world scenarios. It uses the adversarial model and behavior-based clustering techniques to find that it is possible to unveil up to $40 \%$ of Bitcoin user profiles. A solution to this quasi, anonymity has been given by Bonneau et al. (2014) wherein they propose a concept of "Mixcoin" to achieve cryptographic accountability, randomized mixing fees, and an adaptation of mix networks to Bitcoin. The Bitcoin exchange and its associated risk have been mentioned in studies of Moore and Christin (2013) and Li and Wang (2017). It is evident that investors face a massive exchange rate-related risk 
and users with a criminal intention will try to avoid popular exchanges as they are more scrutinized.

Anonymity feature has led this nascent currency in the world of the dark web in recent times and help criminals carry out illegal activities and money laundering. The infamous Silk Road incident was one such evidence. The findings of Stokes (2012), Moser et al. (2013), Meiklejohn et al. (2013), and Blundell-Wignalli (2014) recognize the threat of money laundering which comes as a ramification of Bitcoin design and can attract criminals. A common proposition that finds a place in all these papers is to enhance the transaction-related regulations to curb money laundering and criminal activities. All the papers recommend not to put a complete ban on Bitcoin as that could hinder the technological advancement in this IoT era. The standing of imposing regulations has been mentioned by Brito et al. (2014) and Pieters and Vivanco (2017) in their studies. Brito et al. (2014) while focusing on the legal treatment of traditional securities and Bitcoin-backed derivatives, conclude that financial regulators should consider excluding certain Bitcoin-related financial transactions from regulatory eye watch. They should rather come with measures to enhance resilience and adaptation. Similarly, Pieters and Vivanco (2017) conclude that standard financial regulations can have a quite significant impact on the Bitcoin market. Risk model used in the study by Moser et al. (2014) helps predict the risk of a transaction getting blacklisted by spotting a bad transaction using an open-source knowledge base of the Bitcoin blockchain. This information is available to be overserved by all participants thus making the system more transparent.

There has been repeated mention of two major incidents that portray the downsides, and the immense risk associated with the Bitcoin system: the crash of Mt. Gox and The Silk Road episode. These two have been discussed at length by Trautman (2014) and are valuable a read to get a grasp of these infamous events. Given that the Bitcoin system has managed to be in constant news for defaulting, whether as a bursting bubble or dodging illicit activities, a few major countries have decided to prohibit this cryptocurrency. A Government has the power to prevent an ancillary currency in countries' economy if it enforces severe penalties (Hendrickson and Luther, 2017). Therefore, the government should lead public expectation to keep the confidence to authority and help in reducing the speculation behavior of Bitcoin (and other cryptocurrencies) to stabilize the market (Li et al. 2019).

Bitcoin is thus still in an embryonic phase and needs to evolve with time especially keeping in pace with technological advancements. It should be robust to get accepted as an alternative currency and be able to prevent any fraudulent exploitation.

\section{Conclusion}

This paper systematized the growing research on Bitcoin published. It has segmented the publications on the basis of various elements of economics and finance such as price, demand and supply, market efficiency, volatility and returns, and investment prospects and regulatory aspects. It also highlights the impact of social media on these factors. 
There are a few limitations to this paper. Our study only takes into account research from economics and finance perspective. Technological aspects such as blockchain and mining strategies are not considered. The focus is only on Bitcoin. There are other cryptocurrencies that are merging in the digital market. This study can be extended later to take them into account. The study might have missed out on a few important publications for the reason that it cannot be analyzed from Economics and Finance point of view. Another reason being that new studies keep emerging very frequently and some will become available later.

Based on our research, we enumerate a few observations and recommendations on the basis of gaps observed in the existing research. We notice that most of the findings are methodology and data frequency-dependent. Variations in the results are also observed due to differences in time periods and lack of longer periods of data. Therefore, an exhaustive study can be undertaken to discuss the limitations of different methodologies and its' implications on the results. There are very few country-specific studies conducted. Further analysis can be directed to incorporate geographical boundaries and differences in Bitcoin behavior across them (if any). Regulation norms also vary across different countries and can be analysed. Research focusing on regulatory and legality aspects fails to suggest suitable solutions to make Bitcoin a safer and widely acceptable cryptocurrency to avoid illegal activities. The application of Bitcoin (or cryptocurrency) for the upliftment of economies and financial inclusion needs more exploration. The market for Bitcoin is very dynamic. The prices see a swift change and hence the intrinsic value also changes. Thus, the research needs to be timely updated to analyse the changing trends. The study can be extended to include other areas such as technical aspects and also take in other emerging cryptocurrencies.

Funding This study was not funded.

Data availability statement This study does not use any data. This work is a survey of academic research papers. All the papers used in this work are summarized in tables.

\section{Declarations}

Conflict of interest Parthajit Kayal declares that he has no conflict of interest. Purnima Rohilla declares that she has no conflict of interest.

\section{References}

Aalborg HA, Molnár P, de Vries JE (2019) What can explain the price, volatility and trading volume of Bitcoin? Financ Res Lett 29:255-265

Akhtaruzzaman M, Sensoy A, Corbet S (2020) The influence of bitcoin on portfolio diversification and design. Financ Res Lett 37:101344

Alexander C, Choi J, Park H, Sohn S (2020) BitMEX bitcoin derivatives: Price discovery, informational efficiency, and hedging effectiveness. J Futur Mark 40(1):23-43

Ali R, Barrdear J, Clews R, Southgate J (2014) The economics of digital currencies. Bank Engl Q Bull $54: 276-286$ 
Androulaki E, Karame GO, Roeschlin M, Scherer T, Capkun S (2013) Evaluating user privacy in Bitcoin. International conference on financial cryptography and data security. Springer, Berlin, pp 34-51

Athey S, Parashkevov I, Sarukkai V, Xia J (2016) Bitcoin pricing, adoption, and usage: theory and evidence (No. 17-033). IDEAS working paper series from RePEc. St. Louis. Retrieved from https:// papers.ssrn.com/sol3/papers.cfm?abstract_id=2826674

Aysan AF, Demir E, Gozgor G, Lau CKM (2019) Effects of the geopolitical risks on Bitcoin returns and volatility. Res Int Bus Financ 47:511-518

Baek C, Elbeck M (2015) Bitcoins as an investment or speculative vehicle? A first look. Appl Econ Lett 22(1):30-34

Balcilar M, Bouri E, Gupta R, Roubaud D (2017) Can volume predict Bitcoin returns and volatility? A quantiles-based approach. Econ Model 64:74-81

Barber S, Boyen X, Shi E, Uzun E (2012) Bitter to better-how to make Bitcoin a better currency. International conference on financial cryptography and data security. Springer, Berlin, pp 399-414

Bariviera AF (2017) The inefficiency of Bitcoin revisited: a dynamic approach. Econ Lett 161:1-4

Bariviera AF, Basgall MJ, Hasperué W, Naiouf M (2017) Some stylized facts of the Bitcoin market. Phys A 484:82-90

Baur DG, Dimpfl T (2017) Realized Bitcoin volatility. SSRN 2949754:1-26

Baur DG, Dimpfl T (2019) Price discovery in bitcoin spot or futures? J Futur Mark 39(7):803-817

Baur DG, Hong KJ, Lee AD (2016) Bitcoin-currency or asset? Melbourne Business School. SSRN J. https://doi.org/10.2139/ssrn.2561183

Baur DG, Hong K, Lee AD (2018) Bitcoin: medium of exchange or speculative assets? J Int Finan Markets Inst Money 54:177-189

Becker J, Breuker D, Heide T, Holler J, Rauer HP, Böhme R (2013) Can we afford integrity by proofof-work? Scenarios inspired by the Bitcoin currency. The economics of information security and privacy. Springer, Berlin, pp 135-156

Bedi P, Nashier T (2020) On the investment credentials of bitcoin: a cross-currency perspective. Res Int Bus Financ 51:101087

Beneki C, Koulis A, Kyriazis NA, Papadamou S (2019) Investigating volatility transmission and hedging properties between Bitcoin and Ethereum. Res Int Bus Financ 48:219-227

Bjerg O (2016) How is Bitcoin money? Theory Cult Soc 33(1):53-72

Blau BM (2017) Price dynamics and speculative trading in Bitcoin. Res Int Bus Financ 41:493-499

Blundell-Wignall A (2014) The Bitcoin question: currency versus trust-less transfer technology (No. 37). OECD Publishing, Paris

Böhme R, Christin N, Edelman B, Moore T (2015) Bitcoin: economics, technology, and governance. J Econ Perspect 29(2):213-238

Bonneau J, Narayanan A, Miller A, Clark J, Kroll JA, Felten EW (2014) Mixcoin: anonymity for Bitcoin with accountable mixes. International conference on financial cryptography and data security. Springer, Berlin, pp 486-504

Bouoiyour J, Selmi R (2015) Bitcoin price: is it really that new round of volatility can be on way? Technical report, CATT, University of Pau, France, ESC, Tunis Business School of Tunis, Tunisia, mPRA Paper No. 65580. http://mpra.ub.unimuenchen.de/65580/

Bouoiyour J, Selmi R (2016) Bitcoin: a beginning of a new phase. Econ Bull 36(3):1430-1440

Bouoiyour J, Selmi R, Tiwari AK, Olayeni OR (2016) What drives Bitcoin price. Econ Bull 36(2):843-850

Bouri E, Azzi G, Dyhrberg AH (2016) On the return-volatility relationship in the Bitcoin market around the price crash of 2013. SSRN J. https://doi.org/10.2139/ssrn.2869855

Bouri E, Jalkh N, Molnár P, Roubaud D (2017) Bitcoin for energy commodities before and after the December 2013 crash: diversifier, hedge or safe haven? Appl Econ 49(50):5063-5073

Bouri E, Shahzad SJH, Roubaud D, Kristoufek L, Lucey B (2020) Bitcoin, gold, and commodities as safe havens for stocks: new insight through wavelet analysis. Q Rev Econ Financ 77:156-164

Bradbury D (2013) The problem with Bitcoin. Comput Fraud Sec 2013(11):5-8

Brandvold M, Molnár P, Vagstad K, Valstad OCA (2015) Price discovery on Bitcoin exchanges. J Int Finan Markets Inst Money 36:18-35

Briere M, Oosterlinck K, Szafarz A (2015) Virtual currency, tangible return: portfolio diversification with Bitcoin. J Asset Manag 16(6):365-373

Brito J, Shadab HB, Castillo O'Sullivan A (2014) Bitcoin financial regulation: Securities, derivatives, prediction markets, and gambling. Columbia Science and Technology Law Review. SSRN J. https://doi.org/10.2139/ssrn.2423461 
Bukovina J, Marticek M (2016) Sentiment and Bitcoin volatility (No. 2016-58). Mendel University in Brno, Faculty of Business and Economics.

Cagli EC (2019) Explosive behavior in the prices of Bitcoin and altcoins. Financ Res Lett 29:398-403

Carrick J (2016) Bitcoin as a complement to emerging market currencies. Emerg Mark Financ Trade 52(10):2321-2334

Chaim P, Laurini MP (2019) Is Bitcoin a bubble? Phys A 517:222-232

Chan WH, Le M, Wu YW (2019) Holding Bitcoin longer: the dynamic hedging abilities of Bitcoin. Q Rev Econ Financ 71:107-113

Cheah ET, Fry J (2015) Speculative bubbles in Bitcoin markets? An empirical investigation into the fundamental value of Bitcoin. Econ Lett 130:32-36

Chen C, Liu L, Zhao N (2020) Fear sentiment, uncertainty, and bitcoin price dynamics: The case of COVID-19. Emerg Mark Financ Trade 56(10):2298-2309

Cheung A, Roca E, Su JJ (2015) Crypto-currency bubbles: an application of the Phillips-Shi-Yu (2013) methodology on Mt. Gox Bitcoin Prices. Appl Econ 47(23):2348-2358

Chevapatrakul T, Mascia DV (2019) Detecting overreaction in the Bitcoin market: a quantile autoregression approach. Financ Res Lett 30:371-377

Chiu J, Koeppl TV (2017) The economics of cryptocurrencies-Bitcoin and beyond. SSRN J. https://doi. org/10.2139/ssrn.3048124

Chowdhury A, Mendelson BK (2013) Virtual currency and the financial system: the case of Bitcoin (No. 2013-09). Marquette University, Center for Global and Economic Studies and Department of Economics.

Ciaian P, Rajcaniova M (2016) The digital agenda of virtual currencies: Can Bitcoin become a global currency? ISEB 14(4):883-919

Ciaian P, Rajcaniova M, Kancs DA (2016) The economics of Bitcoin price formation. Appl Econ 48(19):1799-1815

Conlon T, McGee R (2020) Safe haven or risky hazard? Bitcoin during the COVID-19 bear market. Financ Res Lett 35:101607

Corbet S, Lucey B, Yarovaya L (2018) Datestamping the Bitcoin and Ethereum bubbles. Financ Res Lett 26:81-88

Dastgir S, Demir E, Downing G, Gozgor G, Lau CKM (2019) The causal relationship between Bitcoin attention and Bitcoin returns: evidence from the Copula-based Granger causality test. Financ Res Lett 28:160-164

Dwyer GP (2015) The economics of Bitcoin and similar private digital currencies. J Financ Stab 17:81-91

Dyhrberg AH (2016a) Bitcoin, gold and the dollar-A GARCH volatility analysis. Financ Res Lett 16:85-92

Dyhrberg AH (2016b) Hedging capabilities of Bitcoin. Is it the virtual gold? Financ Res Lett 16:139-144

Dyhrberg AH, Foley S, Svec J (2018) How investible is Bitcoin? Analyzing the liquidity and transaction costs of Bitcoin markets. Econ Lett 171:140-143

El Alaoui M, Bouri E, Roubaud D (2019) Bitcoin price-volume: a multifractal cross-correlation approach. Financ Res Lett. https://doi.org/10.1016/j.frl.2018.12.011

Eross A, McGroarty F, Urquhart A, Wolfe S (2019) The intraday dynamics of bitcoin. Res Int Bus Financ 49:71-81

Evans DS (2014) Economic aspects of Bitcoin and other decentralized public-ledger currency platforms. SSRN J. https://doi.org/10.2139/ssrn.2424516

Fang L, Bouri E, Gupta R, Roubaud D (2019) Does global economic uncertainty matter for the volatility and hedging effectiveness of Bitcoin? Int Rev Financ Anal 61:29-36

Folkinshteyn, D., Lennon, M. M., \& Reilly, T. (2015). The Bitcoin mirage: an oasis of financial remittance. J Strateg Int Stud Forthcom

Fry J (2018) Booms, busts and heavy-tails: the story of Bitcoin and cryptocurrency markets? Econ Lett 171:225-229

Fry J, Cheah ET (2016) Negative bubbles and shocks in cryptocurrency markets. Int Rev Financ Anal 47:343-352

Gandal N, Hamrick JT, Moore T, Oberman T (2018) Price manipulation in the Bitcoin ecosystem. J Monet Econ 95:86-96

Garcia D, Schweitzer F (2015) Social signals and algorithmic trading of Bitcoin. R Soc Open Sci 2(9):150288 
Garcia D, Tessone CJ, Mavrodiev P, Perony N (2014) The digital traces of bubbles: feedback cycles between socio-economic signals in the Bitcoin economy. J R Soc Interface 11(99):20140623

Geuder J, Kinateder H, Wagner NF (2019) Cryptocurrencies as financial bubbles: the case of Bitcoin. Financ Res Lett. https://doi.org/10.1016/j.frl.2018.11.011

Giudici P, Abu-Hashish I (2019) What determines bitcoin exchange prices? A network VAR approach. Financ Res Lett 28:309-318

Glaser F, Zimmermann K, Haferkorn M, Weber MC, Siering M (2014) Bitcoin-asset or currency? Revealing users' hidden intentions. In: Proceedings of the 22nd European conference on information systems (ECIS 2014); Tel Aviv, Israel

Griffin JM, Shams A (2020) Is Bitcoin really untethered? J Financ 75(4):1913-1964

Gronwald M (2019) Is Bitcoin a Commodity? On price jumps, demand shocks, and certainty of supply. J Int Money Financ 97:86-92

Hendrickson JR, Luther WJ (2017) Banning Bitcoin. J Econ Behav Organ 141:188-195

Houy N (2014) The economics of Bitcoin transaction fees. GATE WP, 1407, Groupe d'Analyse et de Théorie Economique, Lyon

Iwamura M, Kitamura Y, Matsumoto T (2014a) Is Bitcoin the only cryptocurrency in the town? Economics of cryptocurrency and Friedrich A. Hayek. SSRN J. https://doi.org/10.2139/ssrn.24057 90

Iwamura M, Kitamura Y, Matsumoto T, Saito K (2014b) Can we stabilize the price of a cryptocurrency? Understanding the design of Bitcoin and its potential to compete with Central Bank money. SSRN J. https://doi.org/10.2139/ssrn.2519367

Kajtazi A, Moro A (2019) The role of bitcoin in well diversified portfolios: a comparative global study. Int Rev Financ Anal 61:143-157

Kaminski J (2014) Nowcasting the Bitcoin market with twitter signals. Cambridge. Retrieved from http:// arxiv.org/abs/1406.7577

Kapar B, Olmo J (2019) An analysis of price discovery between Bitcoin futures and spot markets. Econ Lett 174:62-64

Kayal P, Balasubramanian G (2021) Excess volatility in bitcoin: extreme value volatility estimation. IIM Kozhikode Soc Manag Rev. https://doi.org/10.1177/2277975220987686

Kim YB, Kim JG, Kim W, Im JH, Kim TH, Kang SJ, Kim CH (2016) Predicting fluctuations in cryptocurrency transactions based on user comments and replies. PLoS ONE 11(8):e0161197

Kim YB, Lee J, Park N, Choo J, Kim JH, Kim CH (2017) When Bitcoin encounters information in an online forum: Using text mining to analyse user opinions and predict value fluctuation. PLoS ONE 12(5):e0177630

Kliber A, Marszałek P, Musiałkowska I, Świerczyńska K (2019) Bitcoin: safe haven, hedge or diversifier? Perception of bitcoin in the context of a country's economic situation-a stochastic volatility approach. Phys A 524:246-257

Kristoufek L (2013) Bitcoin meets google trends and wikipedia: quantifying the relationship between phenomena of the Internet era. Sci Rep 3:3415

Kristoufek L (2015) What are the main drivers of the Bitcoin price? Evidence from wavelet coherence analysis. PLoS ONE 10(4):e0123923

Kubát M (2015) Virtual currency Bitcoin in the scope of money definition and store of value. Proced Econ Financ 30:409-416

Kurihara Y, Fukushima A (2017) The market efficiency of Bitcoin: a weekly anomaly perspective. J Appl Financ Bank 7(3):57

Klein T, Thu HP, Walther T (2018) Bitcoin is not the New Gold: a comparison of volatility, correlation, and portfolio performance. Int Rev Financ Anal 59:105-116

Li X, Wang CA (2017) The technology and economic determinants of cryptocurrency exchange rates: the case of Bitcoin. Decis Support Syst 95:49-60

Li ZZ, Tao R, Su CW, Lobonţ OR (2019) Does Bitcoin bubble burst? Qual Quant 53(1):91-105

Lo S, Wang JC (2014) Bitcoin as money? vol 14-4. Current Policy Perspectives, Boston

Luther WJ (2016) Bitcoin and the future of digital payments. Indep Rev 20(3):397-404

Luther WJ, White LH (2014) Can Bitcoin become a major currency? SSRN J. https://doi.org/10.2139/ ssrn.2446604

Mai F, Bai Q, Shan J, Wang XS, Chiang RH (2015) The impacts of social media on Bitcoin performance. SSRN J. https://doi.org/10.2139/ssrn.2545957

Matkovskyy R, Jalan A (2019) From financial markets to Bitcoin markets: A fresh look at the contagion effect. Financ Res Lett 31:93-97 
Marimon R, Nicolini JP, Teles P (2012) Money is an experience good: competition and trust in the private provision of money. J Monetary Econ 59(8):815-825

Maurer B, Nelms TC, Swartz L (2013) "When perhaps the real problem is money itself!": the practical materiality of Bitcoin. Soc Semiot 23(2):261-277

Meiklejohn S, Pomarole M, Jordan G, Levchenko K, McCoy D, Voelker GM, Savage S (2013) A fistful of Bitcoins: characterizing payments among men with no names. In: Proceedings of the 2013 Conference on Internet Measurement Conference, ACM, pp 127-140

Moore T, Christin N (2013) Beware the middleman: Empirical analysis of Bitcoin-exchange risk. International conference on financial cryptography and data security. Springer, Berlin, pp 25-33

Möser M, Böhme R, Breuker D (2013) An inquiry into money laundering tools in the Bitcoin ecosystem. In: 2013 APWG eCrime Researchers Summit, IEEE, pp 1-14

Möser M, Böhme R, Breuker D (2014) Towards risk scoring of Bitcoin transactions. International conference on financial cryptography and data security. Springer, Berlin, pp 16-32

Nadarajah S, Chu J (2017) On the inefficiency of Bitcoin. Econ Lett 150:6-9

Nakamoto S (2008) Bitcoin: a peer-to-peer electronic cash system. http://bitcoin.org/bitcoin.pdf, Retrieved 21 Dec 2010

Phillips PC, Shi S, Yu J (2015) Testing for multiple bubbles: historical episodes of exuberance and collapse in the S\&P 500. Int Econ Rev 56(4):1043-1078

Pagnottoni P, Dimpfl T (2019) Price discovery on Bitcoin markets. Digit Financ 1(1):139-161

Pal D, Mitra SK (2019) Hedging bitcoin with other financial assets. Financ Res Lett 30:30-36

Panagiotidis T, Stengos T, Vravosinos O (2019) The effects of markets, uncertainty and search intensity on bitcoin returns. Int Rev Financ Anal 63:220-242

Pichl L, Kaizoji T (2017) Volatility analysis of bitcoin. Quant Financ Econ 1:474-485

Pieters G, Vivanco S (2017) Financial regulations and price inconsistencies across Bitcoin markets. Inf Econ Policy 39:1-14

Polasik M, Piotrowska AI, Wisniewski TP, Kotkowski R, Lightfoot G (2015) Price fluctuations and the use of Bitcoin: an empirical inquiry. Int J Electron Commer 20(1):9-49

Reid F, Harrigan M (2013) An analysis of anonymity in the Bitcoin system. Security and privacy in social networks. Springer, New York, pp 197-223

Richter C, Kraus S, Bouncken RB (2015) Virtual currencies like Bitcoin as a paradigm shift in the field of transactions. Int Bus Econ Res J 14(4):575

Rogojanu A, Badea L (2014) The issue of competing currencies. Case study-Bitcoin. Theor Appl Econ XXI(1):103-114

Sapuric S, Kokkinaki A (2014) Bitcoin is volatile! Isn't that right? International conference on business information systems. Springer, Cham, pp 255-265

Schilling L, Uhlig H (2019) Some simple bitcoin economics. J Monet Econ 106:16-26

Sensoy A (2019) The inefficiency of Bitcoin revisited: a high-frequency analysis with alternative currencies. Financ Res Lett 28:68-73

Shahzad SJH, Bouri E, Roubaud D, Kristoufek L, Lucey B (2019) Is Bitcoin a better safe-haven investment than gold and commodities? Int Rev Financ Anal 63:322-330

Shahzad SJH, Bouri E, Roubaud D, Kristoufek L (2020) Safe haven, hedge and diversification for G7 stock markets: gold versus bitcoin. Econ Model 87:212-224

Shen D, Urquhart A, Wang P (2019) Does twitter predict Bitcoin? Econ Lett 174:118-122

Smales LA (2019) Bitcoin as a safe haven: Is it even worth considering? Financ Res Lett 30:385-393

Stokes R (2012) Virtual money laundering: the case of Bitcoin and the Linden dollar. Inform Commun Technol Law 21(3):221-236

Su CW, Qin M, Tao R, Shao XF, Albu LL, Umar M (2020) Can Bitcoin hedge the risks of geopolitical events? Technol Forecast Soc Change 159:120182

Symitsi E, Chalvatzis KJ (2018) Return, volatility and shock spillovers of Bitcoin with energy and technology companies. Econ Lett 170:127-130

Symitsi E, Chalvatzis KJ (2019) The economic value of Bitcoin: a portfolio analysis of currencies, gold, oil and stocks. Res Int Bus Financ 48:97-110

Tan BS, Low KY (2017) Bitcoin-its economics for financial reporting. Aust Acc Rev 27(2):220-227

Trautman, LJ (2014) Virtual currencies; Bitcoin and what now after Liberty Reserve, Silk Road, and Mt. Gox?. Richmond J Law Technol 20(4):108

Urquhart A (2016) The inefficiency of Bitcoin. Econ Lett 148:80-82

Urquhart A (2017) Price clustering in Bitcoin. Econ Lett 159:145-148 
Urquhart A, Zhang H (2019) Is Bitcoin a hedge or safe haven for currencies? An intraday analysis. Int Rev Financ Anal 63:49-57

Viglione R (2015) Does governance have a role in pricing? Cross-country evidence from Bitcoin markets. SSRN Electr J. https://doi.org/10.2139/ssrn.2666243

Wang J, Xue Y, Liu M (2016) An analysis of Bitcoin price based on VEC model. International conference on economics and management innovations. Atlantis Press, Paris

Wang GJ, Xie C, Wen D, Zhao L (2019) When Bitcoin meets economic policy uncertainty (EPU): Measuring risk spillover effect from EPU to Bitcoin. Financ Res Lett. https://doi.org/10.1016/j. frl.2018.12.028

Weber B (2014) Bitcoin and the legitimacy crisis of money. Camb J Econ 40(1):17-41

Wu S, Tong M, Yang Z, Derbali A (2019) Does gold or Bitcoin hedge economic policy uncertainty? Financ Res Lett 31:171-178

Yelowitz A, Wilson M (2015) Characteristics of Bitcoin users: an analysis of Google search data. Appl Econ Lett 22(13):1030-1036

Yermack D (2015) Is Bitcoin a real currency? An economic appraisal. Handbook of digital currency. Academic Press, London, pp 31-43

Zeng T, Yang M, Shen Y (2020) Fancy Bitcoin and conventional financial assets: Measuring market integration based on connectedness networks. Econ Model 90:209-220 